\title{
Structure Selection and Coordination in Dual-Channel Supply Chains
}

\author{
Cai Jingiing ${ }^{1}$, Wu Jing ${ }^{2}$, Xiao Meidan ${ }^{1}$, Liu Bin $^{3}$, Wang Wenliang ${ }^{1}$ \\ ${ }^{1}$ College of Information and Management Science-Henan Agricultural University (China) \\ ${ }^{2}$ College of Economic Management-Henan Agricultural University (China) \\ ${ }^{3}$ School of Economics and Management-Shanghai Maritime University (China)
}

15803818790@163.com, 13849181505@139.com, xiaomeidan fujian@126.com, liubin@,shmtu.edu.cn, wangwl@,zzuli.edu.cn

Received: November 2014

Accepted: January 2015

\section{Abstract:}

Purpose: This paper investigates the influence of channel structures and channel coordination on the supplier, the retailer, and the entire supply chain in the context of two different kinds of marketing models: the common retailer and the exclusive shop.

Design/methodology/approach: With suppliers who manufacture the alternative commodities and retailers in the dual-channel supply chains as the object of the research, this paper compares suppliers' profits, consumer utility without coordination and contrasts suppliers' and retailers' profits with coordination to determine the range of the revenue sharing rates and which parameters are related.

Findings: The analysis suggests the preference lists of the supplier and the retailer over channel structures with and without coordination are different, and depend on parameters like channel basic demand, channel cost and channel substitutability.

Originality/value: In this research, new sales model for two suppliers should choose the same retailer or the exclusive retailers to sell their commodities.

Keywords: supply chain selection, supply chain coordination, profits, Pareto zone 


\section{Introduction}

In current market environment, the competition among different commodities is becoming more and more fierce. Therefore, for the competitive suppliers, how to choose the structure of the supply chain to increase their own profits and realize the efficiency of entire supply chain seem particularly important. In addition, the suppliers can also cooperate with the downstream retailers to increase their profits, at the same time; retailers tend to make agreements with suppliers to increase their profits, too.

Supplier can sell their commodities through the exclusive shops. For instance, because of its long history and unique brewing process, Maotai is known as the "national wine". Guizhou Maotai group has adopted the marketing mode of Maotai liquor chain stores. As the famous mobile phone manufacturers, Samsung and Apple phones also choose brand stores to sell their commodities. At the same time, suppliers can choose the common retailer to sell their commodities as well. For example, Samsung and Apple not only select the exclusive shops to sell commodities but also put them in the malls such as Gome or Suning who sell the competitors' commodities, too.

The purpose of this paper is to solve the problem in reality, which is without coordination which supply chains the two competitive suppliers should choose to sell their commodities, the common or the exclusive shop, and which kind of structure can bring more profits to suppliers or bring more benefits to consumers. In the case of coordination, whether suppliers and retailers can mutually benefit from the revenue sharing contracts or not and how to determine the range of the revenue sharing rates and which parameters are related.

On the basis of two suppliers who manufacture alternative commodities in dual-channel supply chain, this paper studies the influence of suppliers' profits and the consumer utility without coordination and suppliers' and retailers' profits with coordination under different channel structures. In different market environments, this paper models, optimizes and compares the issue that suppliers should how to choose the sales structures. Through the comparison of the supplier's profits and the whole efficiency of supply chain, this paper provides the foundation for decision-making for the managers of enterprises. Besides, this paper also gets the ranges of revenue sharing rates which supplier and retailer can gain more profits from coordination.

This paper focuses on the selection and cooperation of the dual-channel supply chain. Thus, related literature includes multichannel supply chain competition and cooperation. The literature on multichannel supply chains includes whether a supplier should add a direct channel to its existing retail channel. According to Chiang, Chhajed and Hess (2003), it is beneficial for a supplier to set up a direct channel to compete with its retailer in a model, assuming that consumers have a common positive preference for the local retailer. Chiang et al. (2003) also reports a Pareto zone where both the supplier and the retailer can be better off after the supplier enters the direct channel. The same conclusion is further demonstrated in Arya, Mittendorf and Sappington (2007). Our paper follows this trend but from a different 
perspective with asymmetric base demand in two channels and explores this feature in situations with and without coordination.

Indeed, there has been a large volume of literature focused on channel competition. In a duopoly common retailer channel model, Choi (1996) demonstrates the differences among three game settings, including two Stackelberg games and a vertical Nash game. In a seminal work on a dual exclusive channel, McGuire and Staelin (1983) provide an explanation on why a supplier would want to use an intermediary retailer in the context of two supply chains with one supplier in each chain. Through the theory of channel control, Bucklin (1973) suggests the degree of coordination among players is a measure of the competitive position of that supply chain from the perspectives of payoff, middleman tolerance, and others. EI-Ansary (1974) relaxes some assumptions of Bucklin (1973) and points out that the balanced point of channel power is the interactive result of the channel members. Etgar (1978) empirically suggests a channel control mix aiming for a proper and efficient design of channel control tools for leaders. Nevertheless, the above literature has not explicitly compared the efficacy of different supply chain structures, especially a dual-channel with one common retailer channel and two exclusive retailers' channel, with and without coordination.

The literature on channel coordination is very rich. In a seminal paper on channel coordination, Jeuland and Shugan (1983) discuss difficulties, mechanisms, and solutions in a coordinated system. They also conclude that a quantity discount contract can coordinate the supply chain. Bernstein and Federgruen (2005) generalize a stepwise price-discount-sharing table to a linear wholesale price scheme for non-competing retailers and a non-linear wholesale price scheme for competing retailers. Together with a buyback contract, they demonstrate that a pricediscount-sharing wholesale price contract can coordinate a supply chain with demand uncertainty. In a model with a manufacturer and multiple independent retailers, Ingene and Parry (1995a) demonstrate that a two-part tariff wholesale pricing policy can fully coordinate the channels. Ingene and Parry (1995b) also point out that the manufacture, however, will prefer the second-best two-part tariff to a menu of two-part tariffs maximizing the channel profits. Cachon and Lariviere (2005) apply a revenue sharing contract to coordinate the supply chain with a supplier and a retailer or multiple symmetric retailers competing in quantities. In their model, the supplier and the retailer agree on the revenue sharing percentage and the wholesale price before the retailer determines the optimal order quantity and retail price. They also compare the revenue sharing contract to others and demonstrate that the revenue sharing contract can coordinate a broad array of supply chains. Indeed, many other contract forms have been widely discussed in recent years. One can refer to Cachon (2003) and Tsay, Nahmias and Agrawal (1999) for surveys of contracts for a wide range of supply chain models. However, the above literature has not explicitly addressed full coordination of a dual-channel supply chain including one common retailer and two exclusive retailers. Moreover, few papers have focused on the efficacy of different supply chain structures, especially the impact of the numbers of retailers on the suppliers, the retailers and the entire supply chain, in situations of 
coordination. In this paper, we utilize the revenue sharing contract to demonstrate that negotiation power between the supplier and the retailer of different supply chain structures.

Different from the above researches, Cai(2010) from a different perspective with asymmetric base demand in two channels and explores this feature in situation with and without coordination; explicitly compared the efficacy of different supply chain structures, especially a dual-channel with a retail channel and either a direct channel or a second retail channel, with and without coordination; utilized the revenue sharing contract to demonstrate that negotiation power between the supplier and the retailer varies over different supply chain structures. Cai (2010) investigates the influence of channel structures and channel coordination on the supplier, the retailer, and the entire supply chain in the context of two single-channels and two dual-channel supply chain. His analysis suggests the preference lists of the supplier and the retailer over channel structures with and without coordination are different, and depend on parameters like channel base demand, channel operational costs, and channel substitutability.

Based on the dual-channel model Cai (2010), this paper establishes two dual-channel sales models: one is common retailer sales model; the other is exclusive shop sales model. Different from above literature researches, this paper introduces two competing suppliers, and establishes the dual-channel structure models that the suppliers as the main body of the supply chains. Previous literature researches are focused on the retailers, and the two retailers sharing one supplier, in order to compare whether the supplier should add a direct channel or not. But this paper is focused on that two suppliers should choose the same retailer or the exclusive retailers to sell their commodities, and compare these two sales structures. In the case of with and without contracts, compares the profits of the supplier and the retailer, and determine how to distribute the profits in order to make suppliers and retailers benefit from the coordination.

\section{Modeling Denotations}

Based on two suppliers who manufacture alternative commodities in dual-channel supply chains, this paper studies the influence of suppliers' profits and the consumer utility under different sales structures without coordination. For example, the supplier can choose the "the common retailer" sales structure, or "the exclusive shop" sales structure. And investigates how to determine the proportion of revenue sharing rates with coordination in order to increase both suppliers' and retailers' profits when the suppliers cooperate with the retailers, and the overall supply chain profits is greater than the condition without coordination. Dual-channel structure diagram is shown in Figure 1.

For the sake of simplicity, the $\mathrm{C}$ involved in this paper represents "the common retailer" sales structure; also the $\mathrm{E}$ involved in this paper represents "the exclusive shop" sales structure. Following signs need to be defined during modeling in this paper: 
$p_{i}$ : is the unit retail price of commodity $(i=1,2)$, where $p_{1}$ represents the commodity price of supplier $s_{1}$, and $p_{2}$ represents the commodity price of supplier $s_{2}$.

$w_{i}$ : is the unit wholesale price of commodity $(i=1,2)$, where $w_{1}$ represents the wholesale price of supplier $s_{1}$, and $W_{2}$ represents the wholesale price of supplier $s_{2}$.

$D_{i}$ : is the demand of retailers $\left(i=r_{1}, r_{2}\right)$, where $D_{r 1}$ represents the demand of retailer $r_{1}$, and $D_{r 2}$ represents the demand of retailer $r_{2}$.

$c_{r 1}:$ is the channel operational cost of one exclusive retailer $r_{1}$.

$c_{r 2}:$ is the channel operational cost of the other exclusive retailer $r_{2}$.

$c_{r}$ : is the channel operational cost of the common retailer $r$.

$\alpha_{i}$ : is the base demand of commodity $i(i=1,2)$, where $\alpha_{1}$ represents the base demand of supplier $s_{1}$ 's commodities, and $\alpha_{2}$ represents the base demand of supplier $s_{2}$ 's commodities.

$b$ : is the rate of change of marginal utility and is normalized to one in the sequel for brevity.

$\theta$ : is channel substitutability $(0 \leq \theta<1)$

$\rho$ : is revenue sharing rate of supplier $(0<\rho<1)$

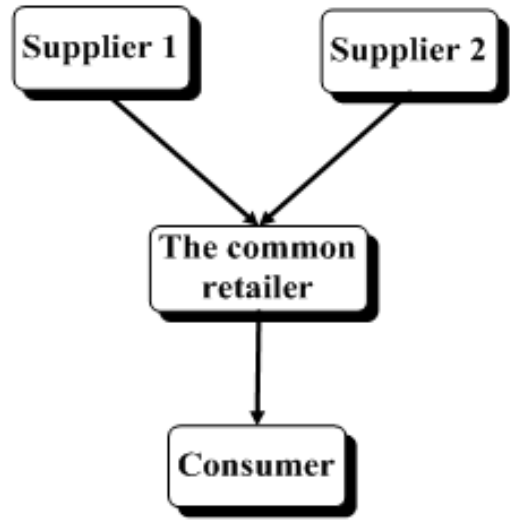

Scenario C

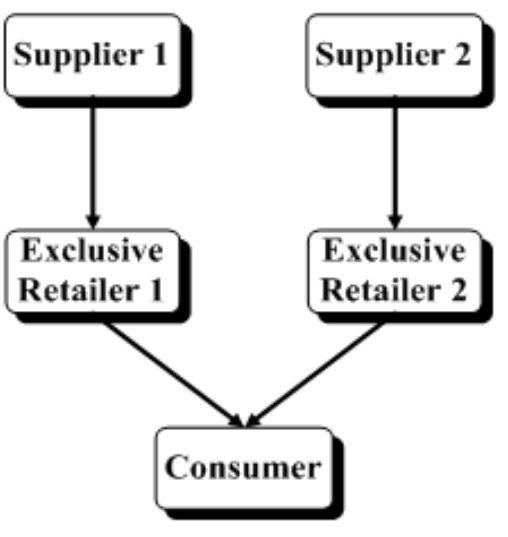

Scenario E

Figure 1. Dual-channel structure

Because consumers usually buy commodities depending on the quantity of the consumer surplus, therefore many literatures established the demand function through the consumer utility theory in dual-channel supply chain. This paper adopts the consumer utility function of Cai (2010), establishes the demand function according to consumer utility function, and assumes that the base demand is always exceed channel operational cost. The channel substitutability $\theta$ is in the range of 0 to 1 , and scenario C's channel operational cost is relatively lower than the scenario E's, so supposed $c_{r} \leq c_{r 1}, c_{r} \leq c_{r 2}$. 


\section{Comparison of Suppliers' Profits under Different Channel Structures without Coordination}

\section{1. "The Common Retailer" Dual-Channel Structure Model (C)}

In the common retailer channel structure, it is assumed that two competitive suppliers choose the same retailer to sell their commodities, which $p_{1}$ represents the retail price of supplier $s_{1}$, $p_{2}$ represents the retail price of supplier $s_{2}$. According to the consumer utility function $U \equiv \sum\left(\alpha_{i} D_{i}-\frac{b D_{i}^{2}}{2}\right)-\theta D_{r 1} D_{r 2}-\sum p_{i} D_{i}\left(i=r_{1}, r_{2}\right)$, can get the demand functions respectively for supplier $s_{1}$ and supplier $s_{2}: D_{r 1-c}=\frac{\alpha_{1}-\theta \alpha_{2}-p_{1}+\theta p_{2}}{1-\theta^{2}}, D_{r 2-c}=\frac{\alpha_{2}-\theta \alpha_{1}-p_{2}+\theta p_{1}}{1-\theta^{2}}$

Then, the profit functions of $s_{1}$ and $s_{2}$ can be expressed as:

$$
\begin{aligned}
& \Pi_{s 1-C}=D_{r 1-C}{ }^{*} w_{1} \\
& \Pi_{s 2-C}=D_{r 2-C}{ }^{*} w_{2}
\end{aligned}
$$

The common retailer's profit function can be indicated as:

$$
\Pi_{r-C}=D_{r 1-C}\left(p_{1}-w_{1}-c_{r}\right)+D_{r 2-C}\left(p_{2}-w_{2}-c_{r}\right)
$$

Lemma 1. The profit functions $\Pi_{s 1-C}, \Pi_{s 2-C}$ are concave to $w_{1}, w_{2}$, and their optimal solution are:

$$
\begin{aligned}
& w_{1-C}^{*}=\frac{\left(-2+\theta+\theta^{2}\right) c_{r}+\left(2-\theta^{2}\right) \alpha_{1}-\theta \alpha_{2}}{4-\theta^{2}} \\
& w_{2-C}^{*}=\frac{\left(-2+\theta+\theta^{2}\right) c_{r}-\theta \alpha_{1}+\left(2-\theta^{2}\right) \alpha_{2}}{4-\theta^{2}}
\end{aligned}
$$

The profit function $\Pi_{r-c}$ is concave to $p_{1}, p_{2}$, and their optimal solutions are:

$$
\begin{aligned}
& p_{1-C}^{*}=\frac{(2+\theta) c_{r}-2\left(-3+\theta^{2}\right) \alpha_{1}-\theta \alpha_{2}}{4-\theta^{2}} \\
& p_{2-C}^{*}=\frac{(2+\theta) c_{r}-\theta \alpha_{1}-2\left(-3+\theta^{2}\right) \alpha_{2}}{2\left(4-\theta^{2}\right)}
\end{aligned}
$$


Based on the optimal price, the optimal demand is $D_{r 1-C}^{*}=\frac{\left(-2+\theta+\theta^{2}\right) c_{r}-\left(-2+\theta^{2}\right) \alpha_{1}-\theta \alpha_{2}}{2\left(4-5 \theta^{2}+\theta^{4}\right)}$, and the optimal profit is $\Pi_{S 1-C}=\frac{\left[\left(2-\theta-\theta^{2}\right) c_{r}+\theta \alpha_{2}+\left(\theta^{2}-2\right) \alpha_{1}\right]^{2}}{2\left(\theta^{2}-4\right)^{2}\left(1-\theta^{2}\right)}$.

\section{2. "The Exclusive Shop" Dual-Channel Structure Model (E)}

In the exclusive shop channel structure, it is assumed that two competitive suppliers choose their own retailers to sell their commodities, which $p_{1}$ represents the retail price of supplier $s_{1}$, $p_{2}$ represents the retail price of supplier $s_{2}$. According to the consumer utility function $U \equiv \sum\left(\alpha_{i} D_{i}-\frac{b D_{i}^{2}}{2}\right)-\theta D_{r 1} D_{r 2}-\sum p_{i} D_{i}\left(i=r_{1}, r_{2}\right)$, can get the demand functions respectively for supplier $s_{1}$ and supplier $s_{2}$ :

$$
D_{r 1-E}=\frac{\alpha_{1}-\theta \alpha_{2}-p_{1}+\theta p_{2}}{1-\theta^{2}}, D_{r 2-E}=\frac{\alpha_{2}-\theta \alpha_{1}-p_{2}+\theta p_{1}}{1-\theta^{2}}
$$

Then, the profit functions of $s_{1}$ and $s_{2}$ can be expressed as:

$$
\begin{aligned}
& \Pi_{s 1-E}=D_{r 1-E}{ }^{*} w_{1} \\
& \Pi_{s 2-E}=D_{r 2-E}{ }^{*} w_{2}
\end{aligned}
$$

The exclusive retailers' profit functions can be indicated as:

$$
\begin{aligned}
& \Pi_{r 1-E}=D_{r 1-E}\left(p_{1}-w_{1}-c_{r 1}\right) \\
& \Pi_{r 2-E}=D_{r 2-E}\left(p_{2}-w_{2}-c_{r 2}\right)
\end{aligned}
$$

Lemma 2. The profit functions $\Pi_{s 1-E}, \Pi_{s 2-E}$ are concave to $\mathrm{w}_{1}, \mathrm{w}_{2}$ and their optimal solution are:

$$
\begin{aligned}
& W_{1-E}^{*}=\frac{\left(-8+9 \theta^{2}-2 \theta^{4}\right) c_{r 1}-\theta\left(-2+\theta^{2}\right) c_{r 2}+\left(8-9 \theta^{2}+2 \theta^{4}\right) \alpha_{1}+\theta\left(-2+\theta^{2}\right) \alpha_{2}}{16-17 \theta^{2}+4 \theta^{4}} \\
& W_{2-E}^{*}=\frac{\theta\left(2-\theta^{2}\right) c_{r 1}+\left(-8+9 \theta^{2}-2 \theta^{4}\right) c_{r 2}+\theta\left(-2+\theta^{2}\right) \alpha_{1}+\left(8-9 \theta^{2}+2 \theta^{4}\right) \alpha_{2}}{16-17 \theta^{2}+4 \theta^{4}}
\end{aligned}
$$


The profit functions $\Pi_{r 1-E}, \Pi_{r 2-E}$ are concave to $p_{1}, p_{2}$, and their optimal solutions are:

$$
\begin{gathered}
p_{1-E}^{*}=\frac{\left(16-14 \theta^{2}+3 \theta^{4}\right) c_{r 1}-2\left(-3+\theta^{2}\right)\left(-\theta\left(-2+\theta^{2}\right) c_{r}+\left(8-9 \theta^{2}+2 \theta^{4}\right) \alpha_{1}+\theta\left(-2+\theta^{2}\right) \alpha_{2}\right)}{64-84 \theta^{2}+33 \theta^{4}-4 \theta^{6}} \\
p_{2-E}^{*}=\frac{\left(-2+\theta^{2}\right)\left(2 \theta\left(-3+\theta^{2}\right) c_{r 1}+\left(-8+3 \theta^{2}\right) c_{r 2}-2 \theta\left(-3+\theta^{2}\right) \alpha_{1}\right)-2\left(-3+\theta^{2}\right)\left(8-9 \theta^{2}+2 \theta^{4}\right) \alpha_{2}}{64-84 \theta^{2}+33 \theta^{4}-4 \theta^{6}}
\end{gathered}
$$

Based on the optimal price, it can be known the optimal demand is:

$D_{r 1-E}^{*}=\frac{\left(-2+\theta^{2}\right)\left(\left(8-9 \theta^{2}+2 \theta^{4}\right) c_{r 1}+\theta\left(-2+\theta^{2}\right) c_{r 2}+\left(-8+9 \theta^{2}-2 \theta^{4}\right) \alpha_{1}-\theta\left(-2+\theta^{2}\right) \alpha_{2}\right)}{64-148 \theta^{2}+117 \theta^{4}-37 \theta^{6}+4 \theta^{8}}$, and the optimal profit is: $\Pi_{S 1-E}=\frac{\left(2-\theta^{2}\right)\left[\theta\left(\theta^{2}-2\right)\left(c_{r 2}-\alpha_{2}\right)+\left(8-9 \theta^{2}+2 \theta^{4}\right)\left(c_{r 1}-\alpha_{1}\right)\right]^{2}}{\left(\theta^{4}-5 \theta^{2}+4\right)\left(4 \theta^{4}-17 \theta^{2}+16\right)^{2}}$.

\section{Comparison of Two Different Channel Structures Without Coordination}

\subsection{Profits Comparative Analysis on Scenario E and Scenario C}

For the comparison of suppliers' profits under different channel structures, according to the different channel cost, they can be divided into three kinds of circumstances. The first circumstance is that the channel costs are equal to zero; the second, channel costs are not equal to zero and $C_{r 1}=C_{r 2}=C_{r}$; the last, channel cost are not equal to zero and $C_{r 1}=C_{r 2} \neq C_{r}$.

\subsubsection{Channel Costs Are Zero}

According to the different base demand, each circumstance can be divided into three kinds:

the base demand for supplier $s_{1}$ is less than supplier $s_{2}$ 's, namely $\frac{\alpha_{1}}{\alpha_{2}}<1$; the base demand for supplier $s_{1}$ and supplier $s_{2}$ 's are equal, namely $\frac{\alpha_{1}}{\alpha_{2}}=1$; the base demand for supplier $s_{1}$ is large than supplier $s_{2}$ 's, namely $\frac{\alpha_{1}}{\alpha_{2}}>1$.

Theorem 1. In order to ensure that all the prices and demands are nonnegative, channel substitutability should under the common boundary $\theta \in[0,0.60)$.

If $C_{r 1}=C_{r 2}=C_{r}=0$, then $\Pi_{E}>\Pi_{C}$. It means that for supplier scenario $E$ outperforms scenario $C$ (as shown in Table 1). 


\begin{tabular}{|c|c|c|}
\hline When $\frac{\alpha_{1}}{\alpha_{\mathbf{2}}}<\mathbf{1}$ & When $\frac{\alpha_{\mathbf{1}}}{\alpha_{\mathbf{2}}}=\mathbf{1}$ & When $\frac{\alpha_{\mathbf{1}}}{\alpha_{\mathbf{2}}}>\mathbf{1}$ \\
\hline$\Pi_{E}>\Pi_{C}$ & $\Pi_{E}>\Pi_{C}$ & $\Pi_{E}>\Pi_{C}$ \\
\hline
\end{tabular}

Table 1 . The profit comparison of different base demands

Based on the above conclusion, can be concluded that when channel costs are zero, the profits of scenario E always outperforms scenario C no matter how the base demands changed. In numerical example, channel substitutability is selected as the independent variable and $\alpha_{1}=5$, $\alpha_{2}=10$ (as shown in Figure 2).

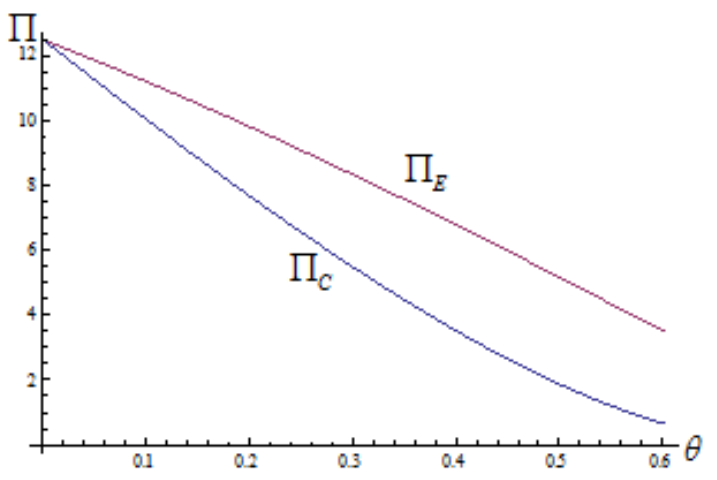

Figure 2. The comparison of suppliers' profits in scenario $\mathrm{E}$ and scenario $\mathrm{C}$

\subsubsection{Channel Costs Are Equal to Each Other and Not Zero}

Theorem 2. In order to ensure that all the prices and demands are nonnegative, channel substitutability should under the common boundary $\theta \in[0,0.60)$.

If $C_{r 1}=C_{r 2}=C_{r} \neq 0$, then $\Pi_{E}>\Pi_{C}$. It means that for supplier scenario $E$ outperforms scenario $C$ (as shown in Table 2).

\begin{tabular}{|c|c|c|}
\hline When $\frac{\alpha_{1}}{\alpha_{\mathbf{2}}}<1$ & When $\frac{\alpha_{\mathbf{1}}}{\alpha_{\mathbf{2}}}=\mathbf{1}$ & When $\frac{\alpha_{\mathbf{1}}}{\alpha_{\mathbf{2}}}>\mathbf{1}$ \\
\hline$\Pi_{E}>\Pi_{C}$ & $\Pi_{E}>\Pi_{C}$ & $\Pi_{E}>\Pi_{C}$ \\
\hline
\end{tabular}

Table 2. The profit comparison of different base demands

Based on the above conclusion, can be concluded that when channel costs are equal to each other, the profits of scenario $\mathrm{E}$ always outperforms scenario $\mathrm{C}$ no matter how the base demands changed. In numerical example, channel substitutability is selected as the independent variable and $\alpha_{1}=5, \alpha_{2}=10$ (as shown in Figure 3). 


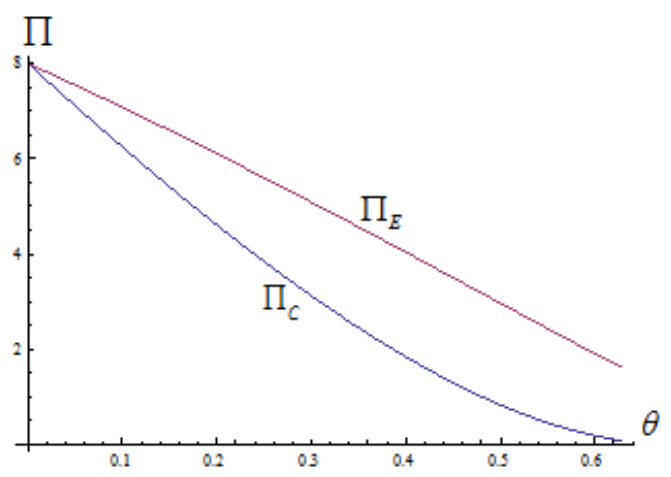

Figure 3. The comparison of suppliers' profits in scenario $E$ and scenario $C$

\subsubsection{Channel Costs Are Not Equal to Each Other and Not Zero}

Theorem 3. In order to ensure that all the prices and demands are nonnegative, channel substitutability should under the common boundary $\theta \in[0,0.60)$.

In the case that $C_{r 1}=C_{r 2} \neq C_{r} \neq 0$, can be obtained: if the value of $\theta$ is smaller, then $\Pi_{C}>\Pi_{E}$, it means that for supplier scenario $C$ outperforms scenario $E$; if the value of $\theta$ is bigger, then $\Pi_{E}>\Pi_{C}$, it means that for supplier scenario E outperforms scenario C (as shown in Table 3 ).

\begin{tabular}{|c|c|c|c|c|c|}
\hline Range of $\theta$ & When $\frac{\alpha_{\mathbf{1}}}{\alpha_{\mathbf{2}}}<\mathbf{1}$ & Range of $\boldsymbol{\theta}$ & When $\frac{\alpha_{\mathbf{1}}}{\alpha_{\mathbf{2}}}=\mathbf{1}$ & Range of $\boldsymbol{\theta}$ & When $\frac{\alpha_{\mathbf{1}}}{\alpha_{\mathbf{2}}}>\mathbf{1}$ \\
\hline$\theta \in[0,0.37]$ & $\Pi_{C}>\Pi_{E}$ & $\theta \in[0,0.36]$ & $\Pi_{C}>\Pi_{E}$ & $\theta \in[0,0.34]$ & $\Pi_{C}>\Pi_{E}$ \\
\hline$\theta \in[0.37,0.60]$ & $\Pi_{E}>\Pi_{C}$ & $\theta \in[0.36,0.60]$ & $\Pi_{E}>\Pi_{C}$ & $\theta \in[0.34,0.60]$ & $\Pi_{E}>\Pi_{C}$ \\
\hline
\end{tabular}

Table 3. The profit comparison of different base demands

Based on the above conclusion, can be concluded that when channel costs are not equal to each other and zero, the profits of the two different channel structures depended on the change of channel substitutability $\theta$, for suppliers, when the range of $\theta$ is smaller, then scenario $C>$ scenario $E$; otherwise, scenario $E>$ scenario $C$. In numerical example, channel substitutability is selected as the independent variable and $\alpha_{1}=5, \alpha_{2}=10$ (as shown in Figure 4). 


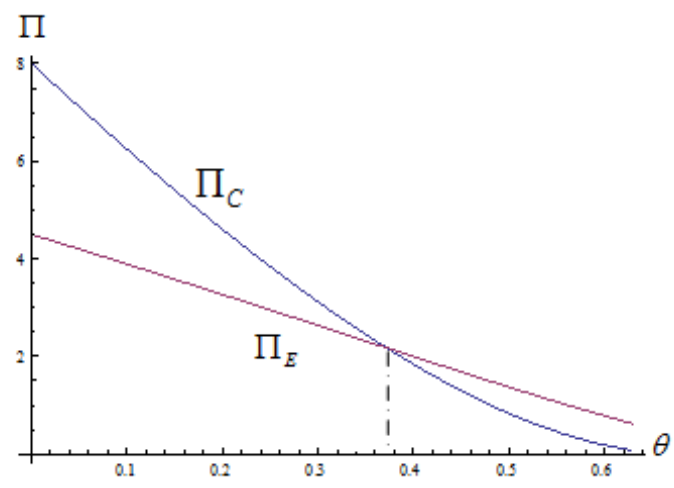

Figure 4. The comparison of suppliers' profits in scenario $\mathrm{E}$ and scenario $\mathrm{C}$

\subsection{Consumer Utility Comparative Analysis on Scenario E and Scenario C}

For the comparison of suppliers' profits under different channel structures, this paper divided into three kinds of circumstances according to the different channel cost. The first circumstance is that the channel cost equals zero; the second, channel cost are not equal to zero and $C_{r 1}=C_{r 2}=C_{r}$; the last, channel cost are not equal to zero and $C_{r 1}=C_{r 2} \neq C_{r}$.

\subsubsection{Channel Costs Are Zero}

According to the different basic demand, each circumstance can be divided into three kinds:

the base demand for supplier $s_{1}$ is less than supplier $s_{2}$ 's, namely $\frac{\alpha_{1}}{\alpha_{2}}<1$; the base demand for supplier $s_{1}$ and supplier $s_{2}$ 's are equal, namely $\frac{\alpha_{1}}{\alpha_{2}}=1$; the base demand for supplier $s_{1}$ is large than supplier $s_{2}$ 's, namely $\frac{\alpha_{1}}{\alpha_{2}}>1$.

Theorem 4. In order to ensure that all the prices and demands are nonnegative, channel substitutability should under the common boundary $\theta \in[0,0.60)$.

If $C_{r 1}=C_{r 2}=C_{r}=0$, then $U_{E}>U_{C}$. It means that for consumer scenario $E$ outperforms scenario C (as shown in Table 4).

\begin{tabular}{|c|c|c|}
\hline When $\frac{\alpha_{1}}{\alpha_{2}}<1$ & When $\frac{\alpha_{1}}{\alpha_{2}}=1$ & When $\frac{\alpha_{1}}{\alpha_{2}}>\mathbf{1}$ \\
\hline$U_{E}>U_{C}$ & $U_{E}>U_{C}$ & $U_{E}>U_{C}$ \\
\hline
\end{tabular}

Table 4. The consumer utility comparison of different base demands 
Based on the above conclusion, it can be concluded that when channel costs are zero, the consumer utility of scenario $\mathrm{E}$ always outperforms scenario $\mathrm{C}$ no matter how the base demands changed. In numerical example, channel substitutability is selected as the independent variable and $\alpha_{1}=5, \alpha_{2}=10$ (as shown in Figure 5).

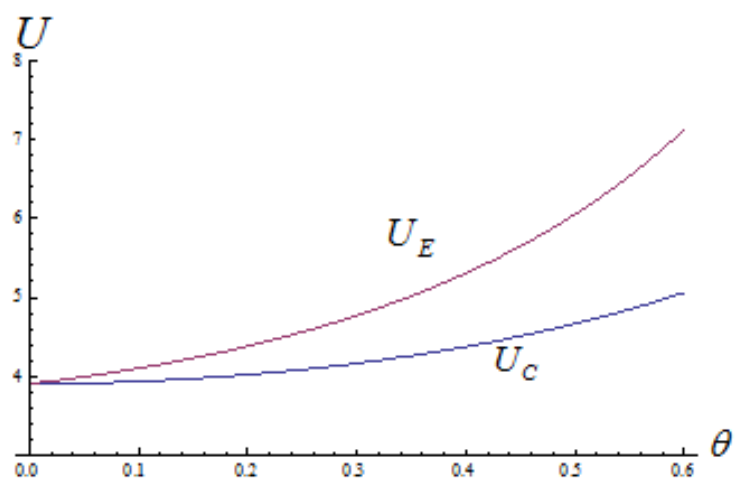

Figure 5. The comparison of consumer utility in scenario $\mathrm{E}$ and scenario $\mathrm{C}$

\subsubsection{Channel Costs Are not Equal to Each Other and Not Zero}

Theorem 5. In order to ensure that all the prices and demands are nonnegative, channel substitutability should under the common boundary $\theta \in[0,0.60)$.

If $C_{r 1}=C_{r 2}=C_{r} \neq 0$, then $U_{E}>U_{C}$. It means that for consumer scenario $\mathrm{E}$ outperforms scenario $C$ (as shown in Table 5).

\begin{tabular}{|c|c|c|}
\hline When $\frac{\alpha_{1}}{\alpha_{2}}<1$ & When $\frac{\alpha_{\mathbf{1}}}{\alpha_{\mathbf{2}}}=\mathbf{1}$ & When $\frac{\alpha_{\mathbf{1}}}{\alpha_{\mathbf{2}}}>\mathbf{1}$ \\
\hline$U_{E}>U_{C}$ & $U_{E}>U_{C}$ & $U_{E}>U_{C}$ \\
\hline
\end{tabular}

Table 5. The consumer utility comparison of different base demands

Based on the above conclusion, it can be concluded that when channel costs are equal to each other, the consumer utility of scenario $E$ always outperforms scenario $C$ no matter how the base demands changed. In numerical example, channel substitutability is selected as the independent variable and $\alpha_{1}=5, \alpha_{2}=10$ (as shown in Figure 6). 


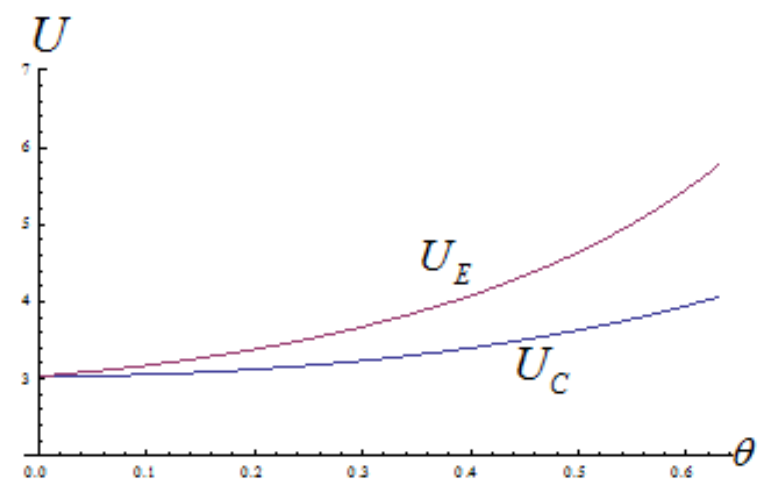

Figure 6. The comparison of consumer utility in scenario E and scenario C

\subsubsection{Channel Costs Are not Equal to Each Other and Not Zero}

Theorem 6. In order to ensure that all the prices and demands are nonnegative, channel substitutability should under the common boundary $\theta \in[0,0.60)$.

In the case that $C_{r 1}=C_{r 2} \neq C_{r} \neq 0$, can be obtained: if the value of $\theta$ is smaller, then $U_{C}>U_{E}$, it means that for supplier scenario $\mathrm{C}$ outperforms scenario $\mathrm{E}$; if the value of $\theta$ is bigger, then $U_{E}>U_{C}$, it means that for supplier scenario $E$ outperforms scenario $C$ (as shown in Table 6).

\begin{tabular}{|c|c|c|c|c|c|}
\hline Range of $\theta$ & When $\frac{\alpha_{1}}{\alpha_{\mathbf{2}}}<1$ & Range of $\theta$ & When $\frac{\alpha_{\mathbf{1}}}{\alpha_{\mathbf{2}}}=\mathbf{1}$ & Range of $\theta$ & When $\frac{\alpha_{\mathbf{1}}}{\alpha_{\mathbf{2}}}>\mathbf{1}$ \\
\hline$\theta \in[0,0.58]$ & $U_{C}>U_{E}$ & $\theta \in[0,0.41]$ & $U_{C}>U_{E}$ & $\theta \in[0,0.31]$ & $U_{C}>U_{E}$ \\
\hline$\theta \in[0.58,0.60]$ & $U_{E}>U_{C}$ & $\theta \in[0.41,0.60]$ & $U_{E}>U_{C}$ & $\theta \in[0.31,0.60]$ & $U_{E}>U_{C}$ \\
\hline
\end{tabular}

Table 6 . The consumer utility comparison of different base demands

Based on the above conclusion, it can be concluded that when channel costs are not equal to each other and zero, the consumer utility of the two different channel structures depended on the change of channel substitutability $\theta$, for consumers, when the range of $\theta$ is smaller, then scenario $C>$ scenario $E$; otherwise, scenario $E>$ scenario $C$. In numerical example, channel substitutability is selected as the independent variable and $\alpha_{1}=5, \alpha_{2}=10$ (as shown in Figure 7). 


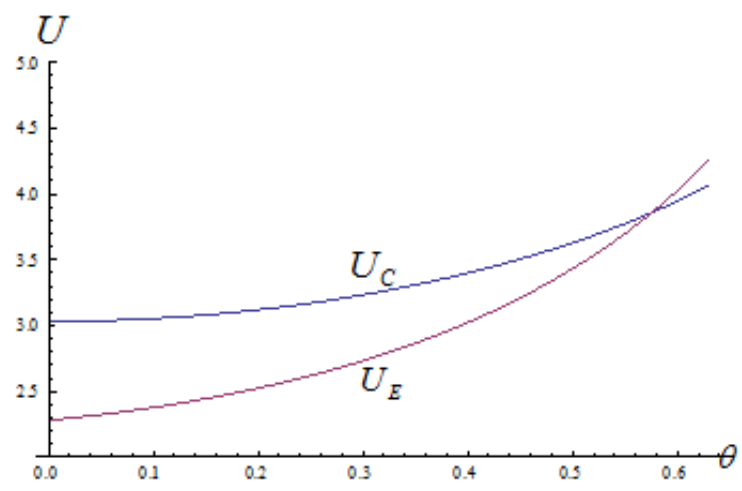

Figure 7. The comparison of consumer utility in scenario E and scenario C

\section{Comparison of Suppliers' and Retailers' Profits under Different Channel Structures with Coordination}

\section{1. "The Common Retailer" Dual-Channel Structure Model without Contract (C)}

In the common retailer channel structure, it is assumed that two competing suppliers choose the same retailer to sell their commodities, which $p_{1}$ represents the retail price of supplier $s_{1}$, $p_{2}$ represents the retail price of supplier $s_{2}$. According to the consumer utility function $U \equiv \sum\left(\alpha_{i} D_{i}-\frac{b D_{i}^{2}}{2}\right)-\theta D_{r 1} D_{r 2}-\sum p_{i} D_{i}\left(i=r_{1}, r_{2}\right)$, can get the demand functions respectively for supplier $s_{1}$ and supplier $s_{2}$ :

$$
D_{r 1-C}=\frac{\alpha_{1}-\theta \alpha_{2}-p_{1}+\theta p_{2}}{1-\theta^{2}}, D_{r 2-C}=\frac{\alpha_{2}-\theta \alpha_{1}-p_{2}+\theta p_{1}}{1-\theta^{2}}
$$

Then, the profit functions of $s_{1}$ and $s_{2}$ can be expressed as:

$$
\begin{aligned}
& \Pi_{s 1-C}=D_{r 1-C}{ }^{*} w_{1} \\
& \Pi_{s 2-C}=D_{r 2-C}{ }^{*} w_{2}
\end{aligned}
$$

The common retailer's profit function can be indicated as:

$$
\Pi_{r-c}=D_{r 1-c}\left(p_{1}-w_{1}-c_{r}\right)+D_{r 2-c}\left(p_{2}-w_{2}-c_{r}\right)
$$

Lemma 1. The profit functions $\Pi_{s 1-C}, \Pi_{s 2-c}$ are concave to $w_{1}, w_{2}$ and their optimal solution are:

$$
\begin{aligned}
& w_{1-C}^{*}=\frac{\left(-2+\theta+\theta^{2}\right) c_{r}+\left(2-\theta^{2}\right) \alpha_{1}-\theta \alpha_{2}}{4-\theta^{2}} \\
& w_{2-C}^{*}=\frac{\left(-2+\theta+\theta^{2}\right) c_{r}-\theta \alpha_{1}+\left(2-\theta^{2}\right) \alpha_{2}}{4-\theta^{2}}
\end{aligned}
$$


The profit function $\Pi_{r-c}$ is concave to $p_{1}, p_{2}$ and their optimal solutions are:

$$
\begin{aligned}
& p_{1-C}^{*}=\frac{(2+\theta) c_{r}-2\left(-3+\theta^{2}\right) \alpha_{1}-\theta \alpha_{2}}{4-\theta^{2}} \\
& p_{2-C}^{*}=\frac{(2+\theta) c_{r}-\theta \alpha_{1}-2\left(-3+\theta^{2}\right) \alpha_{2}}{2\left(4-\theta^{2}\right)}
\end{aligned}
$$

Based on the optimal price, the optimal demand is $D_{r 1-C}^{*}=\frac{\left(-2+\theta+\theta^{2}\right) c_{r}-\left(-2+\theta^{2}\right) \alpha_{1}-\theta \alpha_{2}}{2\left(4-5 \theta^{2}+\theta^{4}\right)}$, the optimal profit of supplier is $\Pi_{S 1-C}=\frac{\left[\left(2-\theta-\theta^{2}\right) c_{r}+\theta \alpha_{2}+\left(\theta^{2}-2\right) \alpha_{1}\right]^{2}}{2\left(\theta^{2}-4\right)^{2}\left(1-\theta^{2}\right)}$, and the optimal profit of retailer is:

$\Pi_{R 1-C}^{*}=\frac{\left(\left(-2+\theta+\theta^{2}\right) c_{r}+2 \alpha_{1}+\theta\left(\theta \alpha_{1}+\alpha_{2}\right)\right)\left(\frac{(2+\theta) c_{r}-2 \alpha_{1}-\theta \alpha_{2}}{2\left(-4+\theta^{2}\right)}\right)+\left(\left(-2+\theta+\theta^{2}\right) c_{r}+2 \alpha_{2}-\theta\left(\alpha_{1}+\theta \alpha_{2}\right)\right)\left(\frac{(2+\theta) c_{r}-\theta \alpha_{1}-2 \alpha_{2}}{2\left(-4+\theta^{2}\right)}\right)}{2\left(-4-5 \theta^{2}+\theta^{4}\right)}$.

\section{2. "The Exclusive Shop" Dual-Channel Structure Model without Contract (E)}

In the exclusive shop channel structure, it is assumed that two competing suppliers choose their own retailers to sell their commodities, which $p_{1}$ represents the retail price of supplier $s_{1}$, $p_{2}$ represents the retail price of supplier $s_{2}$. According to the consumer utility function $U \equiv \sum\left(\alpha_{i} D_{i}-\frac{b D_{i}^{2}}{2}\right)-\theta D_{r 1} D_{r 2}-\sum p_{i} D_{i}\left(i=r_{1}, r_{2}\right)$, can get the demand functions respectively for supplier $s_{1}$ and supplier $s_{2}$ :

$$
D_{r 1-E}=\frac{\alpha_{1}-\theta \alpha_{2}-p_{1}+\theta p_{2}}{1-\theta^{2}}, D_{r 2-E}=\frac{\alpha_{2}-\theta \alpha_{1}-p_{2}+\theta p_{1}}{1-\theta^{2}}
$$

Then, the profit functions of $s_{1}$ and $s_{2}$ can be expressed as:

$$
\begin{aligned}
& \Pi_{s 1-E}=D_{r 1-E}{ }^{*} w_{1} \\
& \Pi_{s 2-E}=D_{r 2-E}{ }^{*} w_{2}
\end{aligned}
$$

The exclusive retailers' profit functions can be indicated as:

$$
\begin{aligned}
\Pi_{r 1-E} & =D_{r 1-E}\left(p_{1}-w_{1}-c_{r 1}\right) \\
\Pi_{r 2-E} & =D_{r 2-E}\left(p 2-w 2-c_{r 2}\right)
\end{aligned}
$$


Lemma 2. The profit functions $\Pi_{s 1-E}, \Pi_{s 2-E}$ are concave to $w_{1}, w_{2}$ and their optimal solution are:

$$
\begin{aligned}
& W_{1-E}^{*}=\frac{\left(-8+9 \theta^{2}-2 \theta^{4}\right) c_{r 1}-\theta\left(-2+\theta^{2}\right) c_{r 2}+\left(8-9 \theta^{2}+2 \theta^{4}\right) \alpha_{1}+\theta\left(-2+\theta^{2}\right) \alpha_{2}}{16-17 \theta^{2}+4 \theta^{4}} \\
& W_{2-E}^{*}=\frac{\theta\left(2-\theta^{2}\right) c_{r 1}+\left(-8+9 \theta^{2}-2 \theta^{4}\right) c_{r 2}+\theta\left(-2+\theta^{2}\right) \alpha_{1}+\left(8-9 \theta^{2}+2 \theta^{4}\right) \alpha_{2}}{16-17 \theta^{2}+4 \theta^{4}}
\end{aligned}
$$

The profit functions $\Pi_{r 1-E}, \Pi_{r 2-E}$ are concave to $p_{1}, p_{2}$ and their optimal solutions are:

$$
\begin{gathered}
p_{1-E}^{*}=\frac{\left(16-14 \theta^{2}+3 \theta^{4}\right) c_{r 1}-2\left(-3+\theta^{2}\right)\left(-\theta\left(-2+\theta^{2}\right) c_{r}+\left(8-9 \theta^{2}+2 \theta^{4}\right) \alpha_{1}+\theta\left(-2+\theta^{2}\right) \alpha_{2}\right)}{64-84 \theta^{2}+33 \theta^{4}-4 \theta^{6}} \\
p_{2-E}^{*}=\frac{\left(-2+\theta^{2}\right)\left(2 \theta\left(-3+\theta^{2}\right) c_{r 1}+\left(-8+3 \theta^{2}\right) c_{r 2}-2 \theta\left(-3+\theta^{2}\right) \alpha_{1}\right)-2\left(-3+\theta^{2}\right)\left(8-9 \theta^{2}+2 \theta^{4}\right) \alpha_{2}}{64-84 \theta^{2}+33 \theta^{4}-4 \theta^{6}}
\end{gathered}
$$

Based on the optimal price, it can be known the optimal demand is:

$$
D_{r 1-E}^{*}=\frac{\left(-2+\theta^{2}\right)\left(\left(8-9 \theta^{2}+2 \theta^{4}\right) c_{r 1}+\theta\left(-2+\theta^{2}\right) c_{r 2}+\left(-8+9 \theta^{2}-2 \theta^{4}\right) \alpha_{1}-\theta\left(-2+\theta^{2}\right) \alpha_{2}\right)}{64-148 \theta^{2}+117 \theta^{4}-37 \theta^{6}+4 \theta^{8}},
$$

the optimal profit of supplier is: $\Pi_{S 1-E}=\frac{\left(2-\theta^{2}\right)\left[\theta\left(\theta^{2}-2\right)\left(c_{r 2}-\alpha_{2}\right)+\left(8-9 \theta^{2}+2 \theta^{4}\right)\left(c_{r 1}-\alpha_{1}\right)\right]^{2}}{\left(\theta^{4}-5 \theta^{2}+4\right)\left(4 \theta^{4}-17 \theta^{2}+16\right)^{2}}$

and the optimal profit of retailer is: $\Pi_{R 1-E}=\frac{\left(-2+\theta^{2}\right)^{2}\left(\left(8-9 \theta^{2}+2 \theta^{4}\right)\left(c_{r 1}-\alpha_{1}\right)+\theta\left(-2+\theta^{2}\right)\left(c_{r 2}-\alpha_{2}\right)\right)^{2}}{\left(1-\theta^{2}\right)\left(64-84 \theta^{2}+33 \theta^{4}-4 \theta^{6}\right)^{2}}$.

\section{3. "The Common Retailer" Dual-Channel Structure Model with Contract (C)}

In the common retailer channel structure, it is assumed that two competing suppliers choose the same retailer to sell their commodities, which $p_{1}$ represents the retail price of supplier $s_{1}$, $p_{2}$ represents the retail price of supplier $s_{2}$. According to the consumer utility function $U \equiv \sum\left(\alpha_{i} D_{i}-\frac{b D_{i}^{2}}{2}\right)-\theta D_{r 1} D_{r 2}-\sum p_{i} D_{i}\left(i=r_{1}, r_{2}\right)$, can get the demand functions respectively for supplier $s_{1}$ and supplier $s_{2}$ :

$$
D_{r 1-C}=\frac{\alpha_{1}-\theta \alpha_{2}-p_{1}+\theta p_{2}}{1-\theta^{2}}, D_{r 2-C}=\frac{\alpha_{2}-\theta \alpha_{1}-p_{2}+\theta p_{1}}{1-\theta^{2}}
$$

Then, the profit functions of $s_{1}$ and $s_{2}$ can be expressed as:

$$
\begin{aligned}
& \Pi_{s 1-C}=D_{r 1-C} *\left(\rho p_{1}+w_{1}\right) \\
& \Pi_{s 2-C}=D_{r 2-C} *\left(\rho p_{2}+w_{2}\right)
\end{aligned}
$$


The common retailer's profit function can be indicated as:

$$
\Pi_{r-C}=D_{r 1-C}\left((1-\rho) p_{1}-w_{1}-C_{r}\right)+D_{r 2-C}\left((1-\rho) p_{2}-w_{2}-c_{r}\right)
$$

Lemma 3. The profit functions $\Pi_{s 1-c}, \Pi_{s 2-c}$ are concave to $w_{1}, w_{2}$, and their optimal solution are:

$$
\begin{aligned}
& w_{1-C}=\frac{(2+\theta)(-2+2 \theta-\rho) c_{r}+2\left(2+\theta^{2}(-1+\rho)-3 \rho\right) \alpha_{1}+\theta(-2+\rho) \alpha_{2}-4\left(-4+\theta^{2}\right) \rho c_{r}}{2\left(4-\theta^{2}\right)} \\
& w_{2-C}=\frac{(2+\theta)(-2+2 \theta-\rho) c_{r}+\theta(-2+\rho) \alpha_{1}+2\left(2+\theta^{2}(-1+\rho)-3 \rho\right) \alpha_{2}-4\left(-4+\theta^{2}\right) \rho c_{r}}{2\left(4-\theta^{2}\right)}
\end{aligned}
$$

For the retailers, in a Nash game can find $p_{1}, p_{2}$, the corresponding optimal prices are given as follows:

$$
\begin{aligned}
& p_{1-C}=\frac{1}{2}\left(\alpha_{1}+C_{r}\right) \\
& p_{2-C}=\frac{1}{2}\left(\alpha_{2}+C_{r}\right)
\end{aligned}
$$

the optimal profit of supplier is:

$$
\Pi_{S 1-E}=\frac{(2-\rho)\left((-1+\theta) c_{r}+\alpha_{1}-\theta \alpha_{2}\right)\left(\left(-2+\theta+\theta^{2}\right) c_{r}+2 \alpha_{1}-\theta\left(\theta \alpha_{1}+\alpha_{2}\right)\right)}{4\left(\theta^{4}-5 \theta^{2}+4\right)}
$$

and the optimal profit of retailer is:

$$
\Pi_{R 1-E}=\frac{2\left(-2+\theta+\theta^{2}\right)(\theta(-1+\rho)-\rho) c_{r}\left(c_{r}+\left(\alpha_{1}+\alpha_{2}\right)\right)+\left(\theta^{2}-2 \rho\right) \alpha_{1}^{2}-2 \theta\left(2+\theta^{2}(-1+\rho)-3 \rho\right) \alpha_{1} \alpha_{2}+\left(\theta^{2}-2 \rho\right) \alpha_{2}^{2}}{4\left(4-5 \theta^{2}+\theta^{4}\right)}
$$

\section{4. "The Exclusive Shop" Dual-Channel Structure Model with Contract (E)}

In the exclusive shop channel structure, it is assumed that two competing suppliers choose their own retailers to sell their commodities, which $p_{1}$ represents the retail price of supplier $s_{1}$, $p_{2}$ represents the retail price of supplier $s_{2}$. According to the consumer utility function $U \equiv \sum\left(\alpha_{i} D_{i}-\frac{b D_{i}^{2}}{2}\right)-\theta D_{r 1} D_{r 2}-\sum p_{i} D_{i}\left(i=r_{1}, r_{2}\right)$, can get the demand functions respectively for supplier $s_{1}$ and supplier $s_{2}$ :

$$
D_{r 1-E}=\frac{\alpha_{1}-\theta \alpha_{2}-p_{1}+\theta p_{2}}{1-\theta^{2}}, D_{r 2-E}=\frac{\alpha_{2}-\theta \alpha_{1}-p_{2}+\theta p_{1}}{1-\theta^{2}}
$$


Then, the profit functions of $s_{1}$ and $s_{2}$ can be expressed as:

$$
\begin{aligned}
& \Pi_{s 1-E}=D_{r 1-E}^{*}\left(\rho P_{1}+w_{1}\right) \\
& \Pi_{s 2-E}=D_{r 2-E}{ }^{*}\left(\rho P_{2}+w_{2}\right)
\end{aligned}
$$

The exclusive retailers' profit functions can be indicated as:

$$
\begin{aligned}
& \Pi_{r 1-E}=D_{r 1-E}\left((1-\rho) p_{1}-w_{1}-c_{r 1}\right) \\
& \Pi_{r 2-E}=D_{r 2-E}\left((1-\rho) p_{2}-w_{2}-c_{r 2}\right)
\end{aligned}
$$

Lemma 4. The profit functions $\Pi_{s 1-E}, \Pi_{s 2-E}$ are concave to $w_{1}, w_{2}$ and their optimal solution are:

$$
\begin{aligned}
& w_{1-E}=\frac{1}{2} \theta(1-\rho)\left(\alpha_{2}-c_{r 2}\right)-\rho c_{r 1} \\
& w_{2-E}=\frac{1}{2} \theta(1-\rho)\left(\alpha_{1}-c_{r 1}\right)-\rho c_{r 2}
\end{aligned}
$$

For the retailers, in a Nash game can find $p_{1}, p_{2}$, the corresponding optimal prices are given as follows:

$$
\begin{aligned}
& P_{1-E}=\frac{1}{2}\left(\alpha_{1}+c_{r 1}\right) \\
& P_{2-E}=\frac{1}{2}\left(\alpha_{2}+c_{r 2}\right)
\end{aligned}
$$

the optimal profit of supplier is: $\Pi_{S 1-E}=\frac{\left(c_{r 1}-\theta c_{r 2}-\alpha_{1}+\theta \alpha_{2}\right)\left(\theta(-1+\rho) c_{r 2}+\rho \alpha_{1}-\theta(-1+\rho) \alpha_{2}-\rho c_{r 1}\right)}{4\left(-1+\theta^{2}\right)}$, and the optimal profit of retailer is: $\Pi_{R 1-E}=\frac{\left(c_{r 1}-\theta c_{r 2}-\alpha_{1}+\theta \alpha_{2}\right)^{2}(1-\rho)}{4\left(1-\theta^{2}\right)}$. 


\section{Profit Distribution Proportion in Different Market Conditions}

\subsection{Profits Distribution Proportion Comparative Analysis on Scenario E and Scenario C}

For the comparison of suppliers' and retailers' profits with and without contracts under two different channel structures, this paper is divided into three kinds of circumstances according to the different channel cost. The first circumstance is that the channel costs are equal to zero; the second, channel costs are not equal to zero and $C_{r 1}=C_{r 2}=C_{r}$; the last, channel cost are not equal to zero and $C_{r 1}=C_{r 2} \neq C_{r}$.

\subsubsection{Channel Costs Are Zero}

According to the different base demand, each circumstance can be divided into three kinds: the base demand for supplier $s_{1}$ is less than supplier $s_{2}$ 's, namely $\frac{\alpha_{1}}{\alpha_{2}}<1$; the base demand for supplier $s_{1}$ and supplier $s_{2}$ 's are equal, namely $\frac{\alpha_{1}}{\alpha_{2}}=1$; the base demand for supplier $s_{1}$ is large than supplier $s_{2}$ 's, namely $\frac{\alpha_{1}}{\alpha_{2}}>1$.

Theorem 7. In order to ensure that all the prices and demands are nonnegative, channel substitutability should under the common boundary $\theta \in[0,0.60)$.

In this case, can get the ranges of revenue sharing rates respectively in the common retailer and the exclusive shop sales models, and the intersection of scenario C and scenario E's revenue sharing rates are the reasonable ranges (as shown in Table 7).

\begin{tabular}{|l|l|}
$\frac{\alpha_{1}}{\alpha_{2}}<1$ & $\rho \in\left(\frac{100 \theta\left(8-5 \theta^{2}+\theta^{4}\right)+125\left(-4-\theta^{2}+\theta^{4}\right)}{2\left(-4+\theta^{2}\right)\left(125+50 \theta\left(-3+\theta^{2}\right)\right)}, 1-\frac{4\left(-2+\theta^{2}\right)^{2}\left(-10 \theta\left(-2+\theta^{2}\right)-5\left(8-9 \theta^{2}+2 \theta^{4}\right)\right)^{2}}{\left(64-84 \theta^{2}+33 \theta^{4}-4 \theta^{6}\right)(-5+10 \theta)^{2}}\right)$ \\
\hline$\frac{\alpha_{1}}{\alpha_{2}}=1$ & $\rho \in\left(\frac{200 \theta\left(8-5 \theta^{2}+\theta^{4}\right)+200\left(-4-\theta^{2}+\theta^{4}\right)}{2\left(-4+\theta^{2}\right)\left(200+100 \theta\left(-3+\theta^{2}\right)\right)}, 1-\frac{4\left(-2+\theta^{2}\right)^{2}\left(-10 \theta\left(-2+\theta^{2}\right)-10\left(8-9 \theta^{2}+2 \theta^{4}\right)\right)^{2}}{\left(64-84 \theta^{2}+33 \theta^{4}-4 \theta^{6}\right)(-10+10 \theta)^{2}}\right)$ \\
\hline$\frac{\alpha_{1}}{\alpha_{2}}>1$ & $\rho \in\left(\frac{400 \theta\left(8-5 \theta^{2}+\theta^{4}\right)+500\left(-4-\theta^{2}+\theta^{4}\right)}{2\left(-4+\theta^{2}\right)\left(500+200 \theta\left(-3+\theta^{2}\right)\right)}, 1-\frac{4\left(-2+\theta^{2}\right)^{2}\left(-10 \theta\left(-2+\theta^{2}\right)-20\left(8-9 \theta^{2}+2 \theta^{4}\right)\right)^{2}}{\left(64-84 \theta^{2}+33 \theta^{4}-4 \theta^{6}\right)(-20+10 \theta)^{2}}\right)$ \\
\hline
\end{tabular}

Table 7. The revenue sharing rates of different base demands

In the range of the revenue sharing rates shown in Table 7, both suppliers and retailers yield more profits under coordination. To ensure both the supplier and retailer will participate in the coordination, the revenue sharing rate should be in a reasonable range (as shown in Table 7); otherwise, the disadvantaged part will deviate from the coordination. 


\subsubsection{Channel Costs Are Equal to Each Other and not Zero}

Theorem 8. In order to ensure that all the prices and demands are nonnegative, channel substitutability should under the common boundary $\theta \in[0,0.60)$.

In this case, can get the ranges of revenue sharing rates respectively in the common retailer and the exclusive shop sales models, and the intersection of scenario C and scenario E's revenue sharing rates are the reasonable ranges (as shown in Table 8 ).

\begin{tabular}{|l|c|}
\hline$\frac{\alpha_{1}}{\alpha_{2}}<1$ & $\rho \in\left(\frac{-28(-1+\theta)^{3}(2+\theta)^{2}+100 \theta\left(8-5 \theta^{2}+\theta^{4}\right)+125\left(-4-\theta^{2}+\theta^{4}\right)}{2\left(-4+\theta^{2}\right)\left(127-3 \theta+\theta^{3}-15(-1+\theta)^{2}(2+\theta)+50 \theta\left(-3+\theta^{2}\right)\right)}, 1-\frac{4\left(-2+\theta^{2}\right)^{2}\left(-9 \theta\left(-2+\theta^{2}\right)-4\left(8-9 \theta^{2}+2 \theta^{4}\right)\right)^{2}}{(-4+9 \theta)^{2}\left(64-84 \theta^{2}+33 \theta^{4}-4 \theta^{6}\right)^{2}}\right)$ \\
\hline$\frac{\alpha_{1}}{\alpha_{2}}=1$ & $\rho \in\left(\frac{-38(-1+\theta)^{3}(2+\theta)^{2}+200 \theta\left(8-5 \theta^{2}+\theta^{4}\right)+200\left(-4-\theta^{2}+\theta^{4}\right)}{2\left(-4+\theta^{2}\right)\left(202-3 \theta+\theta^{3}-20(-1+\theta)^{2}(2+\theta)+100 \theta\left(-3+\theta^{2}\right)\right)}, 1-\frac{4\left(-2+\theta^{2}\right)^{2}\left(-9 \theta\left(-2+\theta^{2}\right)-9\left(8-9 \theta^{2}+2 \theta^{4}\right)\right)^{2}}{(-9+9 \theta)^{2}\left(64-84 \theta^{2}+33 \theta^{4}-4 \theta^{6}\right)^{2}}\right)$ \\
\hline$\frac{\alpha_{1}}{\alpha_{2}}>1$ & $\rho \in\left(\frac{-58(-1+\theta)^{3}(2+\theta)^{2}+400 \theta\left(8-5 \theta^{2}+\theta^{4}\right)+500\left(-4-\theta^{2}+\theta^{4}\right)}{2\left(-4+\theta^{2}\right)\left(502-3 \theta+\theta^{3}-30(-1+\theta)^{2}(2+\theta)+200 \theta\left(-3+\theta^{2}\right)\right)}, 1-\frac{4\left(-2+\theta^{2}\right)^{2}\left(-9 \theta\left(-2+\theta^{2}\right)-19\left(8-9 \theta^{2}+2 \theta^{4}\right)\right)^{2}}{(-19+9 \theta)^{2}\left(64-84 \theta^{2}+33 \theta^{4}-4 \theta^{6}\right)^{2}}\right)$ \\
\hline
\end{tabular}

Table 8 . The revenue sharing rates of different base demands

In the range of the revenue sharing rates shown in Table 8, both suppliers and retailers yield more profits under coordination. To ensure both the supplier and retailer will participate in the coordination, the revenue sharing rate should be in a reasonable range (as shown in Table 8 ); otherwise, the disadvantaged part will deviate from the coordination.

\subsubsection{Channel Costs Are not Equal to Each Other and not Zero}

Theorem 9. In order to ensure that all the prices and demands are nonnegative, channel substitutability should under the common boundary $\theta \in[0,0.60)$.

In this case, can get the ranges of revenue sharing rates respectively in the common retailer and the exclusive shop sales models, and the intersection of scenario $C$ and scenario E's revenue sharing rates are the reasonable ranges (as shown in Table 9).

\begin{tabular}{|l|c|}
\hline$\frac{\alpha_{1}}{\alpha_{2}}<1$ & $\rho \in\left(\frac{-28(-1+\theta)^{3}(2+\theta)^{2}+100 \theta\left(8-5 \theta^{2}+\theta^{4}\right)+125\left(-4-\theta^{2}+\theta^{4}\right)}{2\left(-4+\theta^{2}\right)\left(127-3 \theta+\theta^{3}-15(-1+\theta)^{2}(2+\theta)+50 \theta\left(-3+\theta^{2}\right)\right)}, 1-\frac{4\left(-2+\theta^{2}\right)^{2}\left(-8 \theta\left(-2+\theta^{2}\right)-3\left(8-9 \theta^{2}+2 \theta^{4}\right)\right)^{2}}{(-3+8 \theta)^{2}\left(64-84 \theta^{2}+33 \theta^{4}-4 \theta^{6}\right)^{2}}\right)$ \\
\hline$\frac{\alpha_{1}}{\alpha_{2}}=1$ & $\rho \in\left(\frac{-38(-1+\theta)^{3}(2+\theta)^{2}+200 \theta\left(8-5 \theta^{2}+\theta^{4}\right)+200\left(-4-\theta^{2}+\theta^{4}\right)}{2\left(-4+\theta^{2}\right)\left(202-3 \theta+\theta^{3}-20(-1+\theta)^{2}(2+\theta)+100 \theta\left(-3+\theta^{2}\right)\right)}, 1-\frac{4\left(-2+\theta^{2}\right)^{2}\left(-8 \theta\left(-2+\theta^{2}\right)-8\left(8-9 \theta^{2}+2 \theta^{4}\right)\right)^{2}}{(-8+8 \theta)^{2}\left(64-84 \theta^{2}+33 \theta^{4}-4 \theta^{6}\right)^{2}}\right)$ \\
\hline$\frac{\alpha_{1}}{\alpha_{2}}>1$ & $\rho \in\left(\frac{-58(-1+\theta)^{3}(2+\theta)^{2}+400 \theta\left(8-5 \theta^{2}+\theta^{4}\right)+500\left(-4-\theta^{2}+\theta^{4}\right)}{2\left(-4+\theta^{2}\right)\left(502-3 \theta+\theta^{3}-30(-1+\theta)^{2}(2+\theta)+200 \theta\left(-3+\theta^{2}\right)\right)}, 1-\frac{4\left(-2+\theta^{2}\right)^{2}\left(-8 \theta\left(-2+\theta^{2}\right)-18\left(8-9 \theta^{2}+2 \theta^{4}\right)\right)^{2}}{(-18+8 \theta)^{2}\left(64-84 \theta^{2}+33 \theta^{4}-4 \theta^{6}\right)^{2}}\right)$ \\
\hline
\end{tabular}

Table 9. The revenue sharing rates of different base demands

In the range of the revenue sharing rates shown in Table 9, both suppliers and retailers yield more profits under coordination. To ensure both the supplier and retailer will participate in the 
coordination, the revenue sharing rate should be in a reasonable range (as shown in Table 9); otherwise, the disadvantaged part will deviate from the coordination.

\section{Conclusions}

Following conclusions can be drawn based on the above mentioned comparative analysis:

- For suppliers, in the condition of $C_{r 1}=C_{r 2}=C_{r}=0$, can get the result that the profit of scenario $E$ will be greater than scenario $\mathrm{C}$, no matter how the value of $\theta(\theta \in[0,0.60))$ and $\alpha_{1}, \alpha_{2}$ changed; for consumers, can also get the result that the utility of scenario $E$ will be greater than scenario $C$.

- For suppliers, in the condition of $C_{r 1}=C_{r 2}=C_{r} \neq 0$, can get the result that the profit of scenario $\mathrm{E}$ will be greater than scenario $\mathrm{C}$, no matter how the value of $\theta(\theta \in[0,0.60))$ and $\alpha_{1}, \alpha_{2}$ changed; for consumers, can also get the result that the utility of scenario $E$ will be greater than scenario $\mathrm{C}$.

- For suppliers, in the condition of $C_{r 1}=C_{r 2} \neq C_{r} \neq 0$, the profit of scenario $E$ and scenario $C$ depended on the change of $\theta$. When taking a smaller value of $\theta$, they can get the result that the profit of scenario $C$ will be greater than scenario $E$; when taking a bigger value of $\theta$, they can get the result that the profit of scenario $\mathrm{E}$ will be greater than scenario $\mathrm{C}$. Similarly, for consumers, the utility of scenario $E$ and scenario $C$ depend on the change of $\theta$. When taking a smaller value of $\theta$, they can get the result that the utility of scenario $\mathrm{C}$ will be greater than scenario $\mathrm{E}$; when taking a bigger value of $\theta$, they can get the result that the utility of scenario $\mathrm{E}$ will be greater than scenario $\mathrm{C}$.

- Suppliers and retailers can gain more profits from coordination whether in scenario C or scenario E. So, for suppliers and retailers, within the ranges of revenue sharing rates solved above, participating in the coordination will always outperform than not.

- The above mentioned comparative analysis can be concluded that in the common retailer sales model the suppliers get a greater revenue sharing rate than the retailers, no matter how the market conditions changed. It means that the supplier's negotiation power is higher in the revenue sharing contracts. This conclusion just validates a market phenomenon: the common retailer will be willing to give up some profits to suppliers in order to attract more different suppliers to cooperate with them.

- The above mentioned comparative analysis can be concluded that in the exclusive shop sales model the retailers get a greater revenue sharing rate than the suppliers, no matter how the market conditions changed. It means that the retailer's negotiation power is higher in the revenue sharing contracts. This conclusion just validates a market phenomenon: supplier will be willing to give up some profits to the retailer in 
order to ensure the retailer only sell their products under the condition of revenue sharing contracts.

\section{Acknowledgments}

The authors gratefully acknowledge support from the National Science Foundation of China through Grants U1204701 and 71171074, the Program for Science and Technology Innovation Talents in Universities of Henan Province under Grant 2010HASTIT030, Human-Cultural and Society Science Foundation of Education committee of China under Grant 10YJC630387 and Soft Science Foundation of Henan under Grant 112400450027.

\section{References}

Arya, A., Mittendorf, B., \& Sappington, D.E. (2007). The bright side of supplier encroachment. Marketing Science, 26(5), 651-659. http://dx.doi.org/10.1287/mksc.1070.0280

Bernstein, F., \& Federgruen, A. (2005). Decentralized supply chains with competing retailers under demand uncertainty. Marketing Science, 51(1), 18-29.

Bucklin, L.P. (1973). A theory of channel control. Journal of Marketing, 37(1), 39-47. http://dx.doi.org/10.2307/1250773

Cachon, G. (2003). Supply chain coordination with contracts. In: S. Graves, \& T. de Kok (Eds.), Handbooks in operations research and management science: supply chain management. North Holland: Elsevier Publishing Company.

Cachon, G., \& Lariviere, M. (2005). Supply chain coordination with revenue sharing: Strengths and limitations. Management Science, 51(1), 30-44. http://dx.doi.org/10.1287/mnsc.1040.0215

Cai, G.G. (2010). Channel selection and coordination in dual-channel supply chains. Journal of Retailing, 86(1), 22-36. http://dx.doi.org/10.1016/j.jretai.2009.11.002

Chiang, W.K., Chhajed, D., \& Hess, J.D. (2003). Direct marketing, indirect profits: A strategic analysis of dual-channel supply chain design. Management Science, 49(1), 1-20. http://dx.doi.org/10.1287/mnsc.49.1.1.12749

Choi, S.C. (1996). Pricing competition in a duopoly common retailer channel. Journal of Retailing, 72(2), 117-134. http://dx.doi.org/10.1016/S0022-4359(96)90010-X

EI-Ansary, A.I. (1974). A theory of channel control: revisited. Journal of Marketing, 38(1), 2-7. http://dx.doi.org/10.2307/1250160

Etgar, M. (1978). Selection of an effective channel control mix. Journal of Marketing, 42(3), 53-58. http://dx.doi.org/10.2307/1250534 
Ingene, C., \& Parry, M. (1995a). Channel coordination when retailers compete. Marketing Science, 14(Fall), 360-377. http://dx.doi.org/10.1287/mksc.14.4.360

Ingene, C., \& Parry, M. (1995b). Coordination and manufacturer profit maximization: The multiple retailer channel. Journal of Retailing, 71(Summer), 129-151.

http://dx.doi.org/10.1016/0022-4359(95)90004-7

Jeuland, A.P., \& Shugan, S.M. (1983). Managing channel profits. Marketing Science, 2(3), 239-272. http://dx.doi.org/10.1287/mksc.2.3.239

McGuire, T., \& Staelin, R. (1983). An industry equilibrium analysis of down-stream vertical integration. Marketing Science, 2(2), 161-169. http://dx.doi.org/10.1287/mksc.2.2.161

Tsay, A., Nahmias, S., \& Agrawal, N. (1999). Modeling supply chain contracts: A review. In: S. Tayur, R. Ganeshan, \& M. Magazine (Eds.), Quantitative models for supply chain management, $(17,299-336$, International Series in Operations Research and Management Science c). Norwell, MA: Kluwer Academic Publishers. 